\title{
How Do Markets React to Fundamental Shocks? An Experimental Analysis on Underreaction and Momentum*
}

\author{
Martin Weber, and Frank Welfens ${ }^{1}$
}

This version: October 2007

\begin{abstract}
We perform a market experiment to investigate how average transaction prices react to the arrival of new information. Following a positive shock in fundamental value, prices underreact strongly; following negative shocks we find evidence of a much less pronounced underreaction. After the shock, prices in both situations slowly drift towards the new fundamental value, leading to a characteristic momentum pattern. Controlling for investors' individual disposition effects we form high- and low-disposition markets and prove both underreaction and momentum to be stronger in the high-disposition group. While evidence is mainly in favor of underreaction models like Grinblatt and Han (2005), we conclude based on our findings that positive and negative shocks are not two sides of the same coin and encourage future studies to disentangle the asymmetry between the two situations more carefully.
\end{abstract}

JEL code: C91, D14, D81, G11

\footnotetext{
Financial support from the Deutsche Forschungsgemeinschaft, Sonderforschungsgemeinschaft 504, at the University of Mannheim is gratefully acknowledged.

1 Martin Weber is from the Lehrstuhl für Bankbetriebslehre, Universität Mannheim, L5, 2, 68131 Mannheim, Germany and CEPR, London. E-Mail: weber@bank.BWL.uni-mannheim.de. Frank Welfens is from the Lehrstuhl für Bankbetriebslehre, Universität Mannheim, L5, 2, 68131 Mannheim, Germany. E-Mail: welfens@bank.BWL.uni-mannheim.de.
} 


\section{Introduction}

Behavioral finance basically builds on two research approaches: On one hand, researchers study transaction biases on the individual level, e.g. the disposition effect (Shefrin and Statman 1985), i.e. investors' attitude for selling stocks that trade at a gain and keeping stocks that trade at a loss. On the other hand, behavioral finance tries to prove that markets are not always efficient as proposed by traditional finance theory. Thereby it investigates possible market anomalies like the momentum effect (Jegadeesh and Titman 1993, 2001), i.e. stocks’ tendency for following price trends over intermediate time intervals of three to twelve months. As most market anomalies could also be explained with more complex rational models and arbitrageurs could be more or less successful in offsetting individual investors' misbehavior, it remains unclear, however, how far individual biases actually translate into market outcomes.

We investigate experimentally how markets react to fundamental shocks, i.e. to sudden changes in fundamental value due to new information. If markets were fully efficient we would expect transaction prices to immediately update to the new fundamental value. Conversely, if markets reflect individual investors' biases, transaction prices are either supposed to underreact (Barberis, Shleifer, and Vishny 1998, Grinblatt and Han 2005) or overreact (Daniel, Hirshleifer, and Subrahmanyam 1998, 2001, Hong and Stein 1999, Barberis and Shleifer 2003) to the information, depending on the behavioral model. Following an initial under- or overreaction, prices are usually assumed to exhibit a multi-period price drift into the direction of the new fundamental value, leading to predictability in asset returns and a characteristic momentum pattern. 
As behavioral finance models come to very different pricing implications, and field data studies are unable to observe fundamentals, we still know very little on how changes in fundamental value are actually related to market prices. Moreover, underreaction, overreaction, and momentum could be captured by diverse behavioral assumptions, which field data studies are usually not able to disentangle. These shortcoming, however, can be offset with experimental studies (prominent examples are e.g. Gneezy, Kapteyn, and Potters 2003 and Haigh and List 2005). Our experiment allows us to manipulate fundamental values and to measure reaction in transaction prices under a clean design. We also use the experimental method to sort subjects based on their individual-level biases and to check whether highly biased markets display stronger anomalies. Our approach is inspired by a recent model by Grinblatt and Han (2005), who propose a causal link between individual investors' disposition effects, market price underreaction to fundamental shocks, and momentum price drifts.

In the tradition of Plott and Sunder $(1982,1988)$, subjects in our experiment trade in a single risky asset with state-dependent payouts. Trading between subjects is organized as a single-unit open-book double auction market. After 120 seconds of trading, two of four possible states of nature are eliminated at random, leading to a positive or negative shock in the asset's fundamental value. Trading continues for another 120 seconds succeeding the shock until the final state is determined.

The power of our experimental design (compared to field data studies) lies in the way we control for market disposition. We either measure individual subject's disposition effects in a preceding individual choice task similar to Weber and Camerer (1998) or in the first four rounds in the market experiment. Based on these measures, subjects are then assigned to a high-disposition or low-disposition market, respectively, and trade only with their own kind. 
If underreaction and momentum are related to the disposition effect, we expect both to be stronger in the high-disposition group.

We observe strong and persistent underreaction following positive news and some underreaction following negative news, meaning that average transaction prices tend to be lower (higher) than fundamental value succeeding positive (negative) shocks. While prices in the first seconds following the arrival of new information underreact relatively strongly, they start to revert to the new fundamental value over the following seconds of trading, leading to positive (negative) momentum price drifts after positive (negative) news. Consistent with Grinblatt's and Han's (2005) behavioral assumptions, we also find underreaction and momentum to depend on average market disposition: High-disposition markets are characterized by a significantly stronger underreaction and an insignificantly stronger momentum.

While we report evidence in favor of Grinblatt and Han (2005) and other underreaction models, we conclude that a possible shortcoming of these models lies in their symmetry assumption: As purchasing and selling are, from a behavioral point of view, different decisions, one should not expect positive and negative changes in fundamental value to differ only in signs. Instead, underreaction and momentum should be more pronounced in respect to positive earnings surprises.

This paper proceeds as follows: In section 2, we review related literature on momentum, its explanations, and empirical tests of the Grinblatt and Han (2005) model based on field data. Building on the literature, we also derive our hypotheses. Section 3 describes the experimental design and procedure, and section 4 reports results. Section 5 provides a short discussion of our findings. Translations of the experimental instructions can be found in section 6. 


\section{Related Literature and Hypotheses}

Asset prices are repeatedly documented to exhibit some predictive components. Among others, stock returns are partly explained by past return patterns of the same stock. A long strand of literature e.g. proves stocks to follow positive or negative price trends over intermediate time intervals of approximately three to twelve months, a price pattern termed momentum (see e.g. Jegadeesh and Titman 1993, 2001, Chan, Jegadeesh, and Lakonishok 1996, Rouwenhorst 1998, 1999, Moskowitz and Grinblatt 1999, and Schiereck, De Bondt, and Weber 1999). Zero-investment portfolios long in stocks with high six-month returns and short in stocks with low six-month returns are reported to earn an annually excess return of about $12 \%$ in the following year (Jegadeesh and Titman 1993). Further studies, on the other hand, document price trend reversals over the very short and long run, i.e. within one month and over three to five years (De Bondt and Thaler 1985, Jegadeesh 1990). Both momentum and reversals are of high economic importance as they challenge the assumption of information efficient capital markets (Fama 1970). In the following, we give a brief overview on the most common explanations for the momentum effect, focusing on underreacting stock prices. As we are especially interested in the recently proposed relationship between individual investors' disposition effects and momentum price drifts, we provide a more detailed discussion of the Grinblatt and Han (2005) model and also summarize prior studies on its pricing implications based on field data. We derive our hypotheses in favor with different underreaction models.

Explanations for the momentum effect either follow the rational or the behavioral approach. Following the rational approach, researchers attribute positive excess returns of prior winners to missing risk factors or missing time-variation within traditional market models. As already documented by Jegadeesh and Titman (1993), momentum excess returns are not due 
to positive CAPM betas. In addition, Fama and French (1996) and Jegadeesh and Titman (2001) show that the momentum effect is not captured by Fama's and French's (1993) threefactor asset pricing model. Ang, Chen, and Xing (2006) achieve a better fit with a pricing model based on downside risk, while Chordia and Shivakumar (2002) and Wu (2002) conclude that momentum profits can partly be explained by time-variation in risk exposures. Johnson (2002) develops a theoretical model with dividend growth rate shocks as another non-behavioral explanation. However, due to the fact that standard rational models are unable to capture momentum and more recent models require additional assumptions and an increased number of parameters to incorporate the effect, there is no widespread agreement that momentum profits could be adequately explained on a purely rational basis.

Following the behavioral approach, momentum is assessed as a consistent mispricing due to transaction biases of individual investors that, because of limits of arbitrage (see e.g. Shleifer and Vishny 1997), cannot be fully offset by their rational counterparts. To achieve momentum drifts, behavioral models either assume equilibrium market prices to underreact or to overreact to fundamental shocks. If both concepts are combined, market prices could also oscillate around the new fundamental value with oscillation decreasing over time. Depending on the model, momentum itself manifests as an overreacting price trend or as a long-term reversal back to fundamental value. Figure 1 documents these ideas intuitively.

\section{(please insert figure 1 about here)}

Figure 1 assumes the asset's fundamental value to jump from 100 to 200 currency units at $t=100$. The change in fundamental value may be due to the release of new information that make investors rationally expect an increase in future earnings of the firm. If all market participants were fully rational and there were no market inefficiencies, the equilibrium market price should instantaneously adapt to the new information and equal the new 
fundamental value of 200 currency units from $t=101$ on. Instead, if investors exhibit behavioral biases, prices might either underreact or overreact to the fundamental shock, leading to an intermediate price path predictability. If bad information had entered the market in $t=100$, the graph would be upside down. In this case, underreacting prices would be higher and overreacting prices would be lower than the new fundamental value. In the following, we summarize the models of Daniel, Hirshleifer, and Subrahmanyam (1998, 2001), Barberis, Shleifer, and Vishny (1998), Hong and Stein (1999), Barberis and Shleifer (2003), and Grinblatt and Han (2005), which all focus on different behavioral assumptions that lead to market over- or underreaction and subsequent momentum.

In the single agent model by Daniel, Hirshleifer, and Subrahmanyam (1998), investors are assumed to be overconfident (see e.g. Langer 1975, Svenson 1981, and Lichtenstein, Fischhoff, and Phillips 1982) in the precision of their private signals related to the value of a firm, but not about publicly announced news. In addition, investors suffer from biased selfattribution (Bem 1965, Miller and Ross 1975) and irrationally increase the belief in their own trading ability if subsequent price developments confirm a previous trading decision. On average, public news increases investors' beliefs in their noisy private signals, which makes them trade aggressively in that direction. This, in turn, leads to short-run overreaction and momentum price drifts followed by long-term price reversals to fundamental value as documented by De Bondt and Thaler (1985). In a follow-on paper, the authors again refer to their idea that investors' overconfidence leads to overreaction and momentum, but apply a slightly different mechanism (Daniel, Hirshleifer, and Subrahmanyam 2001).

In contrast to Daniel et al. (1998, 2001), Barberis, Shleifer, and Vishny (1998) assume underreaction instead of overreaction to explain momentum. Their model relies on investors' representativeness bias (Kahneman and Tversky 1973, Tversky and Kahneman 1974) and 
conservatism (Edwards 1965, Greenwald 1980). While asset earnings follow a random walk, investors irrationally believe the asset to be in one of two states: In state 1, earnings revert to the mean, and in state 2, they trend. Although this basic assumption is wrong, investors are assumed to update the probability for both states in a Bayesian manner. Momentum arises if investors assume mean reversion and therefore underreact to earnings news. As this underreaction is not justified by fundamentals and likely to be disproved by future earnings, equilibrium market prices are expected to follow positive (negative) trends succeeding positive (negative) earnings surprises.

The model of Hong and Stein (1999) features two different investor types: News watchers and momentum traders. News watchers observe private signals about fundamental values but do not condition on current or past prices. Momentum traders, on the other hand, base their forecasts solely on the price history. If information about the fundamental value diffuses gradually across the population of news watchers, prices initially underreact to fundamental shocks. Momentum traders observe the price increase and start buying the asset, leading to a momentum price trend into the direction of the new fundamental value and to overreaction in the long run.

Barberis and Shleifer (2003) introduce switchers and fundamental traders as two heterogeneous investor types. Switchers are prone to "style investing”: They group risky assets into a small number of categories called "styles" and allocate their money not to individual assets but to these different asset groups. How much they invest in a style depends on that style's past performance relative to other styles. Conversely, fundamental traders act as arbitrageurs and prevent market prices from moving too far away from their rational value. If good fundamental news about one style enters the market, assets in that style increase in value and attract more and more switchers by their superior past performance, leading to overreac- 
tion and momentum. Prices ultimately revert to fundamental value due to the trades of the fundamental investors, due to bad news for that style, or because of good news for another style driving away the attention of switchers.

Finally, in a more recent model by Grinblatt and Han (2005), momentum and underreaction are explained by market disposition. As our central hypotheses are based on this particular idea, we discuss this model in more detail. Grinblatt and Han assume a single asset economy, with the single asset being in fixed supply of one unit. The asset trades at each point in time, and public news about its fully rational fundamental value $F_{t}$ always arrives just prior to the date-t round of trading. Fundamental value thereby assumes to follow a simple random walk, i.e.

(1) $F_{t+1}=F_{t}+\varepsilon_{t+1}$,

with $\varepsilon_{\mathrm{t}}$ being an uncorrelated random disturbance term mimicking the arise of good $\left(\varepsilon_{\mathrm{t}}>0\right)$ or $\operatorname{bad}\left(\varepsilon_{\mathrm{t}}<0\right)$ news.

Similar to Hong and Stein (1999) and Barberis and Shleifer (2003), Grinblatt and Han assume two representative agents: One rational and one behaviorally affected by prospect theory (Kahneman and Tversky 1979 and Tversky and Kahneman 1992) and mental accounting (Thaler 1980, 1985). The later type derives utility not from absolute wealth but from changes in asset value relative to the average transaction price, and exhibits a lower demand for the single risky asset if he perceives himself to be in the gain domain of his value function, while increasing his demand in the face of losses. Demand functions of rational and behavioral investors are modeled as

(2) $\quad D_{t}^{\text {rational }}=1+b_{t}\left(F_{t}-P_{t}\right)$ and 


$$
D_{t}^{\text {behavioral }}=1+b_{t}\left[\left(F_{t}-P_{t}\right)+\lambda\left(R_{t}-P_{t}\right)\right]
$$

with $P_{t}$ being the price of the asset and $R_{t}$ being the reference price to which behaviorally affected investors evaluate their gains and losses. $\lambda>0$ measures the relative importance of the capital gain component, i.e. in how far behaviorally affected investors are biased. Finally, $b_{t}$ represents the demand functions' slope, i.e. how sensitive both investor types react to deviations from fundamental value or their reference points, respectively. The authors assume $b_{t}$ to be finite so that arbitrageurs cannot fully compensate for behavioral investors' biased demand. The assumption is motivated by limits of arbitrage (see e.g. Shleifer and Vishny 1997).

Whilst information about future dividends enters the market, the demand of behaviorally affected investors prohibits equilibrium market prices to fully update to the new fundamental value. As behavioral investors trade with their rational counterparts, they slowly adjust their reference points into the direction of the new market price, leading to a stepwise correction of their demand and a multi-period momentum drift in equilibrium prices. If $0<\mu<1$ is the fixed fraction of behaviorally affected investors in the market, the equilibrium price solves to be a weighted average of the current fundamental value and the reference price, i.e.

(4) $\quad P_{t}=w F_{t}+(1-w) R_{t} \quad$ with $\quad w=\frac{1}{1+\mu \lambda}$

Hence, the more behaviorally affected investors are in the market and the stronger their bias, the stronger the influence of the reference price on the equilibrium market price.

As the previous literature overview documents, there is an ongoing dissent in behavioral finance theory whether markets in general under- or overreact to new information and how market prices over time adjust to their new fundamental value. Our market experiment tries to shed light on these issues. In agreement with Barberis, Shleifer, and Vishny (1998) 
and Grinblatt and Han (2005), we assume underreacting equilibrium market prices as our benchmark model and propose hypotheses 1a and 1b. If market prices do not underreact but overreact to fundamental shocks, as proposed by Daniel, Hirshleifer, and Subrahmanyam (1998, 2001), Hong and Stein (1999), and Barberis and Shleifer (2003), hypotheses 1a and 1b are expected to fail.

Hypothesis 1a: (Underreaction following gains) Following positive fundamental shocks, average transaction prices are lower than fundamental value.

Hypothesis 1b: (Underreaction following losses) Following negative fundamental shocks, average transaction prices are higher than fundamental value.

Similar to Barberis, Shleifer, and Vishny (1998) and Grinblatt and Han (2005), we also expect market prices to slowly drift towards the new fundamental value, so that underreaction in prices decreases over time. Hypotheses 2a and 2b capture this intuition.

Hypothesis 2a: (Momentum following gains) Following positive fundamental shocks, average transaction prices exhibit a positive drift towards the new fundamental value.

Hypothesis 2b: (Momentum following losses) Following negative fundamental shocks, average transaction prices exhibit a negative drift towards the new fundamental value.

Although the model of Grinblatt and Han (2005) shares its pricing predictions with prior models, it has a couple of unique properties: First, it is based on a well-known behavioral bias that has been shown to be important in the finance context. As first documented by Shefrin and Statman (1985) and proven by a long strand of literature, investors are more 
likely to sell an asset if it trades at a gain rather than at a loss, a transaction pattern named the disposition effect. (See e.g. Odean 1998, Weber and Camerer 1998, Genesove and Mayer 2001, and Garvey and Murphy 2004 for evidence regarding individual stock market investors, student subjects in an individual choice experiment, homeowners, and professional stock market investors, respectively.) Linking pricing anomalies to a well understood behavioral bias seems a promising idea as it allows for knowledge transfer across these disciplines. In addition, the model is relatively parsimonious and provides testable implications for both asset prices and market disposition without requiring too many auxiliary assumptions. Due to the model, the magnitude of underreaction and momentum depends on the fraction of behaviorally affected investors in the market and the degree of their bias. We therefore consider hypotheses 3a and 3b to disentangle the model's story from other possible explanations:

Hypothesis 3a: (Disposition and underreaction) Underreaction is stronger if market participants exhibit strong disposition effects.

Hypothesis 3b: (Disposition and momentum) Momentum price drifts are stronger if market participants exhibit strong disposition effects.

Prior tests of the model are based on field data, either public data on trading volume and prices or individual and professional investors' account level data. In the empirical part of their paper, Grinblatt and Han (2005) test their theoretical model's pricing dynamics with weekly returns, turnover, and market capitalization data of all ordinary common stocks traded at NYSE and AMEX between July 1962 and December 1996. The biased agent's reference point is approximated as past volume-weighted market prices. The authors run a horse race between lagged returns and aggregated capital gains and losses applying Fama and MacBeth (1973) regressions. While lagged returns are able to predict future returns, they fail to be sig- 
nificant once capital gains and losses are controlled for. Moreover, the aggregated capital gains variable is able to explain the $12 \%$ momentum excess return reported by Jegadeesh and Titman (1993). Grinblatt and Han conclude that past returns are only a noisy proxy for aggregated gains and losses and consequently attribute the momentum effect to their market disposition story.

While Grinblatt and Han (2005) base their empirical analysis on aggregated market data, Goetzmann and Massa (2004) and Shumway and Wu (2006) provide more detailed studies on individual transaction-level data. Goetzmann and Massa (2004) try to elicit the time-varying proportion of disposition investors. The authors utilize U.S. discount broker data on over 100,000 accounts for about 86,000 households over the period January 1991 to November 1996 and measure the proportion of disposition trades in each stock as the difference between buys-at-loss and buys-at-gain or sales-at-loss and sales-at-gain, respectively. These variables serve as proxies for the number of disposition investors currently invested in the considered stock. The authors find their disposition proxies to be negatively related to returns, volume, and volatility, confirming the model by Grinblatt and Han (2005). Conversely, Shumway and Wu (2006) study 13,460 accounts at a large Chinese brokerage firm over January 2001 to March 2004. The authors document that, although there is no momentum effect in their sample period, sorting stocks by unrealized gains and losses of disposition-prone investors generates a significant spread of $7 \%$ per year. Finally, Frazzini (2006) investigates the relationship between mutual funds' aggregated capital gains and post-announcement drifts. The analysis is based on end-of-quarter stock holdings of 29,000 mutual funds that either file with the SEC or are global funds and covers the period January 1980 to December 2003. The author shows that price drifts following earnings announcements are most severe whenever aggregated capital gains and the news event are equal in signs. Moreover, the magnitude of the momen- 
tum drift can be explained by capital gains and losses on the event date. A trading strategy based on this finding yields monthly risk-adjusted excess returns of $2 \%$.

\section{Experimental Design}

We apply a computer-based market experiment for investigating whether our underreaction, momentum, and disposition hypotheses hold. While previous field studies test whether aggregated capital gains and losses can explain momentum (see e.g. Goetzmann and Massa 2004, Grinblatt and Han 2005, Shumway and Wu 2006, and Frazzini 2006), they can only indirectly prove that price anomalies are driven by fundamental shocks in combination with some investors' behavioral biases. In the laboratory, unlike in the field, we are able to control for future expectations, fundamental values, and our subjects' disposition effects and thus can apply a more direct test on hypotheses 1 to 3 . The following sections explain our basic design, two different approaches for sorting subjects based on their individual disposition effects, and the experimental procedure in detail.

\subsection{Basic Design}

Our experiment covers seven sessions with every session consisting of ten rounds and 17 to 20 subjects, which are split up into two separate single good markets of approximately equal size. At the beginning of the round, all players obtain five units of the single good and 1,500 units of experimental currency. During the experiment, subjects are allowed to trade with other subjects in the same market in continuous time. Figure 2 shows the computer screen.

(please insert figure 2 about here) 
The basic setup of our experiment is similar to previous market experiments concerned with information aggregation (see e.g. Plott and Sunder 1982, 1988): Each unit of the single good is worth a certain amount of money at the end of the round. The exact value is statedependent. Hence, holding units of the single good is a risky investment. At the beginning of the round, four different states are possible: A, B, C, and D. If at the end of the round state A applies, each unit of the good is worth 100 units of experimental currency. States B, C, and D result in a final value of 200, 300, and 400 currency units, respectively. All states are equally likely and independent from states drawn in previous rounds. Different than many experiments on information aggregation, our subjects all share the same information and are always fully informed about possible payouts and corresponding probabilities.

All rounds are arranged as follows: In a first step, subjects are told of the beginning of the next round and their initial endowment. Next, they have two minutes to trade with each other in a single-unit open-book double auction market. Purchase orders only enter the book if a subject is able to pay the price specified in his order without moving his money account into debt. Selling orders require that the subject currently owns at least one unit of the good. In addition, every subject can only place one purchase and one selling order at a time. If a subject already has one active purchasing or selling order in the book and enters a new one, the old order is replaced. The market is cleared automatically and in continuous time, and the transaction price always equals the price specified in the senior order. Past transaction prices are shown to all participants in the market.

After two minutes, trading is interrupted and subjects are confronted with new information concerning the final value of the good. Therefore, of the four possible states A, B, C, and D we randomly eliminate either the two low-payout states A and B or the two high-payout states $\mathrm{C}$ and $\mathrm{D}$, leading to a positive or negative shock in fundamental value. Positive and negative 
shocks are equally likely as are the two remaining states. Subsequent to this new information, all outstanding orders are cancelled and trading continues for two more minutes. At the end of the round, subjects are informed about the true state and the final value of the single good. Figure 3 summarizes the course of the experiment in a simple flowchart.

\section{(please insert figure 3 about here)}

\subsection{Different Treatments}

We use two different treatments to control for market disposition and to test hypotheses 3a and 3b. In both treatments, we assign our subjects to either a high- or low-disposition market based on the degree of their individual-level disposition effects measured in advance. Those subjects with relatively high disposition effects form one market while those subjects with lower disposition effects are brought together in a second one. This sorting procedure is justified by the finding that individual-level disposition effects are relatively stable within tasks, across tasks, and over time (see Weber and Welfens 2007). The two markets are separated from one another so that highly and lowly biased investors have to interact with their own kind. To enhance comparison of results, shocks in fundamental value are, however, the same for the two markets that constitute one session.

In treatment 1 , individual-level disposition effects are measured in a preceding individual choice experiment, the "stock market design" described in Weber and Welfens 2007. This computer-based experiment replicates the paper-based experiment by Weber and Camerer (1998). Subjects trade in six different goods, which either increase or decrease in value from period to period. Unlike a market experiment, subjects in this experiment do not trade with each other, but on their own. Prices are determined by the computer and subjects can purchase and sell as many units of the goods as they like, as long as their money account 
and their number of units held remain non-negative. While probabilities for price increases are unknown to subjects, they stay constant for every individual good. Hence, goods that increased in value in the past are more likely to exhibit another price increase, and rational subjects should sell their losers and purchase winners. Nevertheless, participants in this experiment usually exhibit the disposition effect (Shefrin and Statman 1985) and sell their winners more readily than their losers. Similar to Odean (1998), we measure individual-level disposition effects for every subject as the difference between proportions of winners and losers realized. For more information on the individual choice task, instructions, the tutorial session, individual-level effects, payments to subjects, and processing time please refer to Weber and Welfens (2007).

In treatment 2, we measure our subjects' disposition effects in the first four rounds of trading within the market experiment. During the first four rounds, subjects are repeatedly assigned randomly to one of the two markets. Starting from round 5 on, they are assigned to either the high-disposition or low-disposition market based on their individual disposition effects in the first four rounds of trading. Disposition measures for treatment 2 are calculated as the number of sales succeeding a positive shock plus the number of purchases succeeding a negative shock divided by the total number of transactions. To enhance comparison across treatments, subjects in treatment 2 also need to participate in the individual choice task discussed above.

\subsection{Procedure}

The experiment was conducted in June 2005 at the University of Mannheim. Our analysis is based on 90 male and 42 female students with approximately half of them studying economics or business administration. The other half's fields of study were not related to eco- 
nomics, e.g. computer science, sociology, or law. The average age was 24; the average academic year was 3.2.

The experiment was programmed in z-Tree (Fischbacher 2007) and was run in a computer laboratory. To make sure that everyone understood the rules and computer screens, subjects not only had to read the instructions but also had to go through a short tutorial session. In the tutorial, they learned how to read the price information presented on the screen and how to place and accept orders. The average processing time for the whole market experiment was approximately 50 minutes, including time for reading instructions and participating in the tutorial.

For determining a subject's payoff, we chose one round randomly. Financial reward for participating in the market experiment equaled $0.3 \%$ of final wealth, which, in turn, was calculated of a subject's money account at the end of the round, plus the final value of the single good multiplied with the number of units held by this subject. The average payout was $€$ 8.24, with a standard deviation of $€ 1.87$. The entire experiment was held in German. A translation of the instructions and the tutorial can be found in the appendix.

\section{Results}

In the following, we test for underreaction succeeding fundamental shocks (section 4.2) and momentum price drifts following an initial underreaction (section 4.3). In addition, we test whether Grinblatt's and Han’s (2005) explanation holds, i.e. whether high-disposition markets show stronger anomalies (section 4.4). All tests are based on transaction data, on which we first report descriptive statistics (section 4.1). 


\subsection{Descriptive Statistics}

Our experimental data set covers seven sessions with each session consisting of one high-disposition and one low-disposition market group. Every market group trades in ten rounds of 240 seconds each, which leaves us with 140 individual rounds or 560 minutes of trading. Over the course of the experiment, our subjects place a total of 17,595 orders leading to 3,733 transactions. In line with other market experiments documented in the literature (see e.g. Plott and Sunder 1982, 1988, and Bossaerts, Plott, and Zame 2006), subjects are engaged in excessive trading even in an environment where, from a rational point of view, they should have only traded on differences in risk attitudes.

Preceding the fundamental shock, i.e. in the first 120 seconds of trading, we count 2,105 single-unit transactions between subjects, which correspond to 15.04 pre-shock transactions per round or one transaction every 7.98 seconds. The standard deviation in average transactions per round is 4.05 ; the median is 15 . While trading volume already appears to be high, subjects' order placement is even more pronounced. In the first 120 seconds, every market generates an average of 34.06 purchasing orders and 34.99 selling orders, meaning a rapidly changing order book with one new order every 1.74 seconds. Succeeding positive or negative news, i.e. in the later 120 seconds of the round, markets trade an average (median) of 11.82 or 11.46 (12 or 11 ) times per round, or every 10.15 to 10.47 seconds. Every market group places an average (median) of 27.36 (27) purchasing orders and 30.00 (29) selling orders after a positive shock and 27.32 (26.5) purchasing orders in combination with 28.66 (29) selling orders following a negative fundamental shock. Standard deviations in the four cases vary between 6.75 for purchasing offers after positive news and 8.34 for purchasing offers following negative news. While volume is significantly higher in the first 120 seconds of trading than after the arrival of new information ( $\mathrm{p}=0.0000$, using a ranksum test), trading activ- 
ity does not considerably differ following positive and negative changes in fundamental value $(p=0.4433)$. The same picture emerges for subjects' order placement $(p=0.0000$ and $p=$ $0.5420)^{2}$

Those subjects who purchased some additional units of the single good during the first 120 seconds of trading, sell an average of 0.59 units succeeding the arrival of new information. Conversely, subjects who ended the pre-shock trading period with less than their initial five units, on average, purchase 0.59 units over the later 120 seconds following the shock. These effects do not systematically depend on whether the shock was positive or negative.

For the following analyses of market underreaction and momentum it is also of importance how orders and transactions spread over time. We therefore split the 120 seconds preceding or succeeding the shock in six intervals of 20 seconds each and calculate the average number of purchasing orders, selling orders, and transactions per interval and round. Table 1 documents the results for the first 120 seconds before the shock as well as for positive and negative shocks separately. We do not report medians as these differ only marginally from the average.

\section{(please insert table 1 about here)}

2 As the above-mentioned figures imply, not all orders lead to transactions between subjects. Only approximately $26 \%$ (23\%) of all purchasing (selling) offers are executed in the second they are submitted by subjects, while $18 \%$ (19\%) first enter the order book for some seconds and are matched with new incoming orders. (Some matched purchasing and selling orders arrived in the same second of trading.) $15 \%$ (14 \%) are automatically taken off the order book due to the arrival of new information in the middle of the 240 seconds trading period or due to the end of the trading round. Finally, a considerable proportion of $41 \%$ ( $44 \%$ ) is eliminated because the considered subject himself placed a new order with a new price. 
Preceding the fundamental shock, trading activity decreases slightly over time, while succeeding positive and negative news, volume is relative stable, even though on a lower level. Order placement, on the other hand, abates strongly in all three situations from the first to the last time interval. This, however, is not surprising as subjects in the first interval start with an empty order book and need to place their initial purchasing and selling offers. Later on, they only need to place a new order if the old one is executed or they changed their evaluation of the good. In sum, our experimental markets seem to be alive and relatively liquid over the whole 240 seconds of trading.

\subsection{Underreaction}

Figure 4 shows average transaction prices preceding the shock as well as following positive and negative changes in fundamental value. We calculate averages per trading second and fit an asymptotic function to each graph that captures the underlying trend. The fitting function follows the form proposed by Camerer (1987) and applied e.g. in Camerer, Loewenstein, and Weber (1989), i.e.

$$
P_{t}=\alpha+\beta \cdot P_{t-1}=\alpha \sum_{i=0}^{t-1}\left(\beta^{i}\right)+\beta^{t} \cdot P_{0}
$$

with $P_{t}$ being the model's predicted average transaction price in second $t$, and $\alpha, \beta$, and $P_{0}$ representing three degrees of freedom. The asymptotic equilibrium price solves as $\alpha /(1-\beta)$.

\section{(please insert figure 4 about here)}

It is obvious that prices react differently given positive or negative news about the asset's final value. While preceding the shock and following a positive shock, transaction prices are clearly below the expected value, following a negative shock, prices start above expected 
value and only decrease slowly over time. ${ }^{3}$ We now want to explore the nature and causes of these differences in detail.

Testing for underreaction, i.e. hypotheses $1 \mathrm{a}$ and $1 \mathrm{~b}$, requires specifying which time interval to analyze and how underreaction measures are calculated. Underreaction, in theory, should be assessed as the difference between fundamental value and actual transaction prices, with fundamental value, in turn, being a function of the distribution of future dividends and market risk aversion. While one advantage of the experimental method is that we are able to control for future dividends, we cannot perfectly quantify market risk premiums. However, we may get a good estimate of market risk aversion by investigating transaction prices over the last seconds preceding the shock. If we assume that prices tend to equilibrate over time, prices in the last interval before the arrival of new information, i.e. over seconds 101 to 120 , should best reflect how risk averse our market participants are on aggregate. Transaction prices over the last 20 seconds preceding the shock are consistent with a market risk premium of 5.23 experimental currency units. If, in addition, we consider that risk is higher before rather than after the shock, ${ }^{4}$ we can expect an after-shock risk premium considerable lower than 5.23 .

3 Fitting leads to $\mathrm{P}_{0}=239.32, \alpha=19.16$, and $\beta=0.92$ for transaction prices before the shock; $\mathrm{P}_{0}=318.76$, $\alpha=24.67$, and $\beta=0.93$ for transaction prices following a positive shock; and $\mathrm{P}_{0}=151.57, \alpha=0.66$, and $\beta=0.995$ for transaction prices following a negative shock. Due to this model, equilibrium prices solve as 244.65, 337.20, and 141.31, respectively.

4 Preceding the shock, every unit of the single good corresponds to a lottery that either leads to a payout of 400, 300, 200, or 100 currency units, with all realizations being equally likely. When the new information arrives in the middle of the trading round, expected values either increase or decrease by 100 currency units, 
For the following analysis we assume a risk premium of 1 currency unit. ${ }^{5}$ Assuming a different premium leads to a parallel shift in underreaction measures but does not affect our main findings concerning differences in positive and negative shocks or market disposition. The underreaction measure $U_{i}$ of transaction $i$ is thus defined as

$$
U_{i}= \begin{cases}\left(E_{i}-1\right)-T_{i} & \text { if } E_{i}=350 \\ T_{i}-\left(E_{i}-1\right) & \text { if } E_{i}=150\end{cases}
$$

for positive and negative fundamental shocks, respectively. $E_{\mathrm{i}}$ stands for the expected value and $\mathrm{T}_{\mathrm{i}}$ for the transaction price of transaction $\mathrm{i}$.

i.e. from 250 to 350 in the case of a positive or from 250 to 150 in the case of a negative shock. Succeeding a positive shock, each unit represents a lottery between 400 and 300 currency units, while following a negative shock the lottery is between 200 and 100 currency units, respectively. The final determination of the asset's value leads to a payout 50 currency units higher or lower than its current expected value. Hence, the intermediate shock is more risky than the determination of the asset's final value.

5 From a purely rational point of view, we should not expect any risk aversion in the laboratory, as payouts are very low compared to subjects’ real life income. Explaining the observed market risk aversion therefore requires the assumption that subjects ignore their real life income and naively optimize their utility as a function of experimental payouts. If we, for example, consider our subjects to exhibit a power function $\mathrm{x}^{\gamma}$, the observed risk premium of 5.23 currency units in the pre-shock lottery would be consistent to $\gamma \approx 0.81$. Based on this parameterization, risk premiums should be relatively low succeeding the arrival of new information, i.e. only 0.69 currency units in the case of a positive and 1.65 currency units in the case of a negative fundamental shock. For the following analysis, we assume the same risk premium of 1 currency unit following gains and losses, as this is a more intuitive and conservative way for testing our hypotheses. Allowing for different risk premia in the two situations leads to even stronger results. 
We start testing for undereaction by comparing transaction prices over the whole 120 trading seconds succeeding the shock. Following a positive fundamental shock, average (median) transaction prices are 14.83 (13) currency units below fundamental value. A significant majority of 647 of a total of 780 trades $(82.95 \%)$ are at underreacting prices $(p=0.0000){ }^{6}$ Succeeding a decrease in fundamental value, transactions lead to average (median) underreaction measures of -0.36 (1) currency units and only 505 of 848 trades (59.55 \%) underreact (p $=0.0000)$. In addition, a ranksum test reveals that underreaction following positive shocks is stronger than underreaction following negative shocks $(\mathrm{p}=0.0000)$.

For a more detailed test, we split the after-shock trading period of 120 seconds into six time intervals of 20 seconds each. We then repeat the same procedure as done for the whole data set for each of these intervals. Table 2 provides the results. There is strong and persistent underreaction succeeding positive shocks, with mean (median) underreaction measures lasting from 19.80 (16) currency units in the first interval to 11.41 (11) currency units in the last 20 seconds of the round. Although the absolute degree of underreaction decreases steadily over time, even after 100 trading seconds over $82 \%$ of all trades are at prices below fundamental value. The effect is highly significant for every time interval. Conversely, following a decrease in fundamental value, median transaction prices underreact only marginally, while

6 Our test statistics implicitly assume that transaction prices are independent. This assumption may not hold perfectly. In principle, every transaction price reflects the evaluations and trading decisions of one buyer and one seller. Due to the fact that markets are organized as single-unit auctions, the same buyer and seller might interact two or more times in a row to exchange more than just one unit of the asset. In this situation, one should expect autocorrelation across transaction prices. As this, on average, happens only once per round, we, however, do not believe this to be a problem here. 
means only underreact during the first 40 seconds after the shock. Nevertheless, for all but one time interval a significant majority of transactions occur at underreacting prices.

\section{(please insert table 2 about here)}

While our underreaction hypotheses are supported by our data, we also find a significant difference between positive and negative news that is not covered by behavioral finance models. Equilibrium market prices are usually assumed to react symmetrically to positive and negative changes in fundamental value (see e.g. Barberis, Shleifer, and Vishny 1998 and Grinblatt and Han 2005). Table 2 instead reports underreaction to be much stronger in the first situation. We formally test this hypothesis using a ranksum test and report highly significant p-values for each time interval in the last column.

We think that the difference in underreaction is quite intuitive. If, following a positive shock, two investors trade with each other at underreacting prices, the seller is a normal disposition effect investor. Due to the increased stock price and his still low reference point he becomes increasingly risk averse and accepts to sell his stocks even if he needs to pay a premium to the less biased counterpart. If, following a negative shock, the two investors trade at underreacting prices, the buyer is the biased one as he, due to his still high reference point, is willing to pay too much for the asset. Assuming symmetry between the two situations would be equivalent to assuming purchasing and selling to be perfect mirror images. We do not believe that this is the case. Instead, we assume sales to be much more behaviorally affected, as the current owner shares a longer history with the asset, from the purchase decision over intermediate price changes to the final sale. 


\subsection{Momentum}

When looking at figure 4, one gets the impression that transaction prices following positive (negative) changes in fundamental value exhibit some positive (negative) momentum drifts. As predicted by Barberis, Shleifer, and Vishny (1998), Grinblatt and Han (2005), and our hypotheses $2 \mathrm{a}$ and $2 \mathrm{~b}$, underreacting prices, on average, appear to revert to the new fundamental value. Following negative shocks, average transaction prices seem to reach this new fundamental value over time, while following positive shocks, prices stabilize on a lower level.

We perform a statistical test for momentum effects in a similar way as done for underreaction. For all rounds exhibiting underreacting prices, we measure momentum price drifts as the difference between average transaction prices in the first 20 and the last 20 seconds of the after-shock trading period. On average (median), following a positive shock, transaction prices climb 6.34 (5.23) currency units between the first 20 and the last 20 trading seconds with $62.16 \%$ of all rounds exhibiting positive price momentum $(p=0.0939)$. Conversely, succeeding a negative shock, transaction prices drop 5.61 (5) currency units and $68.75 \%$ of all price paths decrease over time $(p=0.0251)$. However, in contrast to our underreaction analysis, momentum effects are not stronger following positive news ( $\mathrm{p}=0.9276)$.

To find out how momentum evolves over time, we again split the 120-seconds trading periods into six intervals of 20 seconds each and measure momentum price drifts from interval to interval. As table 3 reports, there is a distinct momentum at least in the first 40 seconds following a positive fundamental shock. Within the first 40 seconds, prices climb an average (median) of 6.93 (4.17) currency units into the direction of the new fundamental value. With over $75 \%$ of all rounds exhibiting positive price drifts, the effect is highly economically and statistically significant $(\mathrm{p}=0.0013)$. Although not significant over succeeding time intervals, 
prices, on average, tend to continue this trend. Similarly, following a decrease in fundamental value, price drifts are negative for all time intervals. Momentum effects start at $-2.83(0.00)$ currency units over the first 40 seconds and end up at -0.02 (0.00) currency units over seconds 81 to 120 . The effect is statistically significant between the second and fourth time interval. Again, momentum is not reported to be systematically stronger for positive or negative shocks.

\section{(please insert table 3 about here)}

In summary, we are able to conditionally support hypotheses 2a and 2b: Following a positive (negative) shock in fundamental value, transaction prices tend to exhibit some positive (negative) price trend. The magnitude of price drifts decreases over time as if transaction prices approach the new fundamental value asymptotically. While all momentum effects are correct in signs, significance can be found only over the first 80 seconds following the fundamental shock. In addition, whereas one would expect a full reversal to the new fundamental value, following a positive shock, transaction prices stabilize on a lower level.

\subsection{Underreaction and Momentum in High-Disposition and Low-Disposition Markets}

While we find a significant underreaction following both positive and negative shocks in fundamental value and some evidence of momentum price drifts especially in the first half of the after-shock trading period, we still do not know why market prices exhibit both properties.

Grinblatt and Han (2005) propose market disposition to be the driving factor behind these anomalies. To show how disposition effects could move equilibrium market prices, they assume two very different representative agents, one rational and one behaviorally affected (compare equations 2, 3, and 4). In reality, however, individual investors can hardly be as- 
signed to one of the two groups. Although stock market investors and experimental subjects are reported to vary in their individual-level biases, there are almost no individual investors that could be classified as purely rational (Weber and Welfens 2007). Due to the fact that we do not get a rational investor group in the laboratory, we sort all subjects based on their individual disposition effects and propose the auxiliary assumption that low-disposition (highdisposition) groups exhibit a bigger (smaller) proportion of rational trades. Our approach is still in line with Grinblatt's and Han's idea and demand functions but assumes investors to follow mixed strategies, with lowly biased investors being more likely to invest rationally. The parameter $\mu$ in equation 4 would thus not capture the fixed fraction of behaviorally affected investors, but subjects' probability to follow the biased demand function given in equation 3.

Individual disposition effect measures are elicited as described in section 3.2, i.e. either in a preceding individual choice experiment (treatment 1) or in the first four rounds of trading within the market experiment (treatment 2). In treatment 1, 28 subjects are assigned to the three low-disposition markets and 29 subjects to the three high-disposition markets. Mean (median) individual-level disposition measures vary widely across the two groups with -0.08 $(-0.07)$ for the lowly and $0.37(0.35)$ for the highly biased market. Standard deviations in disposition measures are 0.29 and 0.22 . Similarly, in treatment 2 , the four low-disposition markets are set up with 38 subjects exhibiting an average (median) bias of 0.22 (0.19) with a standard deviation of 0.21 . The high-disposition markets, likewise, lead to mean (median) 
measures of $0.73(0.73)$ with a standard deviation of $0.23 .^{7}$ Besides these strong differences in market disposition, markets do not systematically differ in age, years of study, number of finance courses taken, or proportions of male and female investors.

Figures 5 and 6 show average transaction prices per second following positive and negative shocks for both high- and low-disposition markets separately. Figure 5 corresponds to treatment 1 with subjects being assigned to one of the two markets based on their transaction decisions in the preceding individual choice experiment. For figure 6, subjects were sorted based on the first four rounds of trading within the market experiment.

\section{(please insert figures 5 and 6 about here)}

First, most market groups exhibit underreacting prices and a certain degree of momentum into the direction of the new fundamental value, especially in the first half of the aftershock trading period. Second, consistent with the model and hypothesis 3a, underreaction seems to be more pronounced in the two high-disposition markets. The effect may be best documented by the asymptotic fit, which for the high-disposition market following positive (negative) shocks almost always lies below (above) the fitted function of the low-disposition market. Based on the asymptotic model given in equation 5, equilibrium market prices in figure 5 are 339.59 and 342.85 currency units for the high- and low-disposition market following positive shocks. Following negative shocks, equilibrium prices are 148.20 and 142.91 , respectively. In figure 6, equilibrium prices solve as 336.30 and 336.28 for positive, and 151.88 and

7 Disposition measures should not be compared across treatments as these measures are defined differently. While disposition measures for treatment 1 are solely based on subjects’ selling behavior, measures in treatment 2 capture both purchases and sales to replicate the prospect theory agent assumed by Grinblatt and Han (2005). 
148.40 for negative shocks. Concerning momentum price drifts, differences between groups are less obvious.

We formally test for differences in underreaction by calculating average underreaction measures in transaction prices separately for both high- and low-disposition markets and both types of sorting. Table 4 provides the results for positive and negative shocks in fundamental value.

\section{(please insert table 4 about here)}

Disposition matters. The table reveals that underreaction is higher in highly rather than lowly biased markets, regardless of how subjects are sorted. ${ }^{8}$ Following a positive shock, the two markets underreact quite strongly. Nevertheless, the difference between average transaction prices and fundamental value is significantly bigger in the high-disposition-effect group. Following a decrease in fundamental value, only high-disposition markets seem to underreact on average, while low-disposition markets exhibit average transaction prices at or below fundamental value. The difference in underreaction, however, is less pronounced and vanishes in medians.

Differences in momentum are tested in a similar way: For all rounds exhibiting underreacting prices, we calculate the difference between average transaction prices over the first and the last 20 seconds in the 120-seconds trading period succeeding the shock. We then compare average momentum price drifts between high-disposition and low-disposition markets. Table 5 reports the results.

8 Note that underreaction measures may not be compared across sorting procedures as the two treatments do not follow the same sequence of shocks. 


\section{(please insert table 5 about here)}

As expected, positive shocks consistently lead to positive and negative shocks to negative price momentum. In accordance with hypothesis 3b, absolute momentum price drifts also partly depend on market participants’ individual biases. A ranksum test fails to be significant as our data set in table 5 is split up into eight market groups, leaving us with too few trading rounds per group.

Consistent with the difference in momentum price drifts, high-disposition markets lead to higher volatility than low-disposition markets. Under the first sorting procedure, standard deviations in transaction prices following positive shocks are 14.17 and 13.55 currency units in the high-disposition and low-disposition markets ( $\mathrm{p}=0.0658$ using a robust Levene test). Following a negative shock, standard deviations are 13.46 and $11.71(\mathrm{p}=0.5402)$. If subjects are sorted based on the first four rounds of trading, standard deviations are 14.24 and 10.07 succeeding an increase in fundamental value $(\mathrm{p}=0.0007)$, as well as 13.22 and 10.60 ( $p=0.0312)$ succeeding a decrease. Concerning trading volume, there are no systematic differences between high-disposition and low-disposition markets or positive and negative fundamental shocks.

\section{Discussion}

We apply a simple market experiment studying how transaction prices react to the arrival of new information, leading to sudden changes in fundamental value. We show that average transaction prices underreact to new information but do so in an asymmetric way: While following positive shocks, underreaction is strong and persistent, following a decrease in fun- 
damental value, prices underreact to only a small amount and for a short period. In addition, we find some evidence for momentum following both positive and negative news. Transaction prices following positive (negative) shocks show positive (negative) drifts towards the new fundamental value, with the effect being significant over the first 80 seconds of the aftershock trading period. Finally, we test whether underreacting market prices and momentum price drifts are due to market disposition. We sort subjects either based on their behavior in a preceding individual choice experiment or on their transactions over the first four rounds of trading within the market experiment and show that both underreaction and momentum are indeed more pronounced if market participants exhibit stronger individual-level disposition effects.

Our interpretation is as follows: First, most of our results are in line with models of stock price underreaction, e.g. Barberis, Shleifer, and Vishny (1998) and Grinblatt and Han (2005), and reject models that assume markets to overreact to new information, e.g. Daniel, Hirshleifer, and Subrahmanyam (1998, 2001), Hong and Stein (1999), and Barberis and Shleifer (2003). The finding that underreaction and momentum depend on market disposition is especially important as behavioral finance is rarely able to document that individual-level biases translate into market outcomes. Second, however, we do not believe in symmetric reactions. While behavioral underreaction models assume positive and negative news to be followed by underreaction and momentum of the same extent, our data reveals a significant difference between the two cases. Due to the market disposition story, behavioral investors are supposed to act as sellers succeeding a positive shock but as buyers succeeding a negative shock. As behavioral finance generally assumes selling decisions to be more biased than purchasing decisions, one should instead expect stronger underreaction and momentum following positive rather than negative changes in fundamental value. 
Our study contributes to the literature not only by reporting evidence on underreaction, momentum, and a recent model's behavioral assumptions but also by providing another starting point for future research. As fundamental shocks in our experiment lead to asymmetric reactions, it seems fruitful to go back to the field and to study whether similar differences can be observed succeeding e.g. earnings surprises. In addition, even if disposition effects explain part of stock price momentum, we are, of course, not sure whether it is the only driving factor. While other momentum models are based on other behavioral variables (see section 2), another promising idea is to use our experimental design but to sort subjects by some other quality, e.g. their overconfidence, biased self-attribution, or conservatism. We believe that the combination of eliciting behavioral biases on the individual level and sorting subjects into markets based on these variables provides a powerful general method for analyzing the relationship between individual behavior and market outcomes. The procedure could be easily adapted to other individual biases and different market anomalies. 


\section{Appendix: Instructions}

This section contains translations of the German instructions and the computer tutorial for the market experiment. Besides these special instructions, subjects also received general instructions, and instructions for the preceding individual choice task as reported in Weber and Welfens (2007). The instructions for the market experiment are taken from treatment 2. Treatment 1 only varied in the sorting procedure.

On the following pages, we explain the procedure of the game. Please read these instructions carefully. Your financial reward depends on your success in this game.

You are playing this game together with all the other players who are currently present in the laboratory. The game consists of a total of ten rounds. In each of the first four rounds, the players present in this laboratory are divided randomly into two equal sized groups. From round 5 on, the groups remain the same until the end of the game. You play every round only with the other players in your group. Together with the other players of your group, you form a market. At the beginning of each run, all players receive five units of goods as well as 1,500 monetary units. With your goods and money, you can trade with the other players in your group, i.e. purchasing units from other players or selling units to other players.

At the end of each run, every unit of the good is worth a certain amount of experimental money. The value of each unit is unknown, however, at the beginning of the round. The exact value is determined in the following way: At the end of the round, one of four states occurs at random: State A, B, C, or D. At the beginning of the round, all states are equally likely. If state A occurs, each unit has a final value of 100 monetary units. If state B occurs, every unit is worth 200 units of experimental money. In state C, each unit of the good has a value of 300 and in state D of 400 monetary units. 
Every round proceeds as follows: First, you are told in an information screen that a new run is going to start. Then you have two minutes to trade with the other players in your market. For this, you can make purchase and selling offers. At the same time, you see the current offers of all other players in your market. Whenever a purchase and selling offer match, i.e. the price of the purchase offer is equal or higher than the price of the selling offer, a trade is settled automatically between these two players. The transaction price is always the price of the older bid. The buyer automatically pays the price to the seller, and a unit of the good is automatically transferred from the seller to the buyer. Both offers are then taken off the market and the transaction price is shown to all market participants.

After two minutes, trading is interrupted and all players receive new information about the value of the traded good. For this, you and all other players in your market are informed that either one of the states A and B or one of the states C and D occurs at the end of the round. The remaining two states are still equally likely. After this new information, you have two more minutes to trade with the other players in your market in the way described above. After these two minutes, the round ends. On an information screen, you are told which of the two states actually occurred and the final value of the good. The game consists of a total of ten such rounds.

To determine your financial reward for this game, one of the ten rounds is chosen randomly. Your payoff equals $0.3 \%$ of your final wealth at the end of this round. Your final wealth consists of your money account plus the value of your goods.

On the following pages, we show you the elements of the computer screen. 
In the following, we present the text of the computer tutorial, which was the same for the two treatments. In the tutorial, subjects see the game screen and are asked to place and accept orders.

You are looking at the game screen. At the top, you can see that this is a "Test Run". Please click “ok”.

In the right upper corner you see a little box with the remaining time in seconds. You always trade with the other players in your market for 120 seconds. As soon as this time is expired, all players leave the trading screen automatically. For this test run, we expanded the time to 500 seconds so that you have enough time to get to know all parts of the screen.

The screen is divided into a left and a right part. On the left side you see some information about the future value of the traded good, your current holdings of this good, as well as your current money account. On the right side, you see the current offers to buy or sell, recent transaction prices, as well as an input box and two buttons for making your own bids.

Please look at the top left box. This box again shows the information you know from the instructions: The value of the good is determined at random. At the beginning, each of the four states is still possible. In the course of a round, after you have traded with the other players for two minutes, you learn that only two of the four states remain possible: Either A and B or C and D. The box in the top left-hand corner is updated accordingly. After this new information, you have again two minutes to trade with the other players in your market.

Underneath this box, you see two more little boxes. The first shows your current holding of the good. In the second box, you see your current amount of money. At the beginning of each round, you always have five units of goods and 1,500 monetary units on your account. If you trade with other players in your market, i.e. if you purchase or sell goods, these boxes adapt automatically. 
Now please look at the right side, which is labeled "Market". Among other things, you can see three gray boxes. Later, the first gray box will show the selling offers, and the second one the bids for purchasing. In these boxes you can see the prices at which a potential seller or buyer is willing to sell or buy. The bids always refer to one unit of goods.

The bids for selling are arranged with ascending order of prices, which means that the bid with the lowest selling price is placed at the top. The bid with the highest price is placed at the bottom. In contrast, the bids for purchasing are arranged with decreasing prices. This means that the purchasing bid with the highest price is placed at the top of the box, whereas the one with the lowest price is to be found at the bottom. If you have made an own bid for selling or purchasing, this bid also appears in the box for offers to sell or to buy. Your bid appears in blue, whereas the bids of the other players appear in black. This ensures that you are able to distinguish your bid from the other players’ bids.

In the third gray box, you later see latest transaction prices, i.e. prices at which transactions have already been settled between players in the market in this round. Transaction prices are arranged chronologically. The most recent transaction price is displayed on top. The second latest is displayed underneath the latest price and so on.

A transaction is settled between two players if the price at which a buyer is willing to purchase is higher or equal to the price a seller is willing to sell at. The bargain is closed based on the price of the senior bid. As soon as a transaction is settled, both bids vanish from the two boxes with purchase and selling offers. This means that they are no longer available. At the same time, the transaction price immediately appears in the gray box containing "Last transaction prices”.

In the bottom right-hand corner, you see another box. With the help of this box, you can create your own purchasing and selling offers. For this, you just enter the price at which you are 
willing to buy or sell in the box named "Price". Then you click on the button "Submit purchasing offer" if you are willing to buy at this price or on the button "Submit selling offer" if you are willing to sell at this price. If your offer immediately leads to a transaction between you and another player in the market, you only see that the other player's offer is taken off the market and that a new entry is added to the box "Last transaction prices". If your offer does not immediately lead to a transaction, it remains in the corresponding gray box.

You can only have one purchase and one selling offer in the market at a time. If you already made a bid for selling or buying and then make a new one, your old offer is eliminated automatically. This means that you just have to make a new offer if you want to change the price at which you are willing to purchase or sell. Please notice that it does not make sense if the price you are willing to buy at is higher than the one you are willing to sell at. Therefore, the program does not accept such offers.

Please try it out now: Create a purchase or selling offer! Very good. You created a purchase offer. Your offer is now displayed in the box containing purchase offers in blue color. Let us assume another player in the market would be willing to sell a good but claims a price which is one currency unit higher than your current bid. Please click on "ok" to make the computer create such an order automatically for this test run.

Additionally, let us assume you want to accept the other player's offer. Please increase the price of your purchase offer by at least one monetary unit and observe what happens.

Very good! You have now accepted the offer. As you can see, the two bids have vanished from the market and a new transaction price has been added to the list "Last transaction prices”. Furthermore, your holdings of goods and your money account have been updated. Please click on "ok" now to leave the test run and start the real game. 


\section{References}

Ang, Andrew, Joe Chen, and Yuhang Xing (2006): Downside risk, Review of Financial Studies, Vol. 19, No. 4, 1191-1239.

Barberis, Nicholas and Andrei Shleifer (2003): Style investing, Journal of Financial Economics, Vol. 68, No. 2, 161-199.

Barberis, Nicholas, Andrei Shleifer, and Robert Vishny (1998): A model of investor sentiment, Journal of Financial Economics, Vol. 49, No. 3, 307-343.

Bem, Daryl L. (1965): An experimental analysis of self-persuasion, Journal of Experimental Social Psychology, Vol. 1, No. 3, 199-218.

Bossaerts, Peter, Charles Plott, and William R. Zame (2006): Prices and allocations in financial markets: Theory and experiment, working paper.

Camerer, Colin F. (1987): Do biases in probability judgment matter in markets? Experimental evidence, American Economic Review, Vol. 77, No. 5, 981-997.

Camerer, Colin F., George Loewenstein, and Martin Weber (1989): The curse of knowledge in economic settings: An experimental analysis, Journal of Political Economy, Vol. 97, No. 5, 1232-1254.

Chan, Louis K. C., Narasimhan Jegadeesh, and Josef Lakonishok (1996): Momentum strategies, Journal of Finance, Vol. 51, No. 5, 1681-1713.

Chordia, Tarun and Lakshmanan Shivakumar (2002): Momentum, business cycle, and timevarying expected returns, Journal of Finance, Vol. 57, No. 2, 985-1019.

Daniel, Kent D., David Hirshleifer, and Avanidhar Subrahmanyam (1998): Investor psychology and security market under- and overreaction, Journal of Finance, Vol. 53, No. 6, 1839-1885.

Daniel, Kent D., David Hirshleifer, and Avanidhar Subrahmanyam (2001): Overconfidence, arbitrage, and equilibrium asset pricing, Journal of Finance, Vol. 56, No. 3, 921-965. 
De Bondt, Werner F. M. and Richard H. Thaler (1985): Does the stock market overreact?, Journal of Finance, Vol. 40, No. 3, 793-805.

Edwards, Ward (1968): Conservatism in human information processing, in: Benjamin Kleinmutz (ed.): Formal representation of human judgment, New York, John Wiley and Sons, 17-52.

Fama, Eugene F. (1970): Efficient capital markets: A review of theory and empirical work, Journal of Finance, Vol. 25, No. 2, 383-417.

Fama, Eugene F. and James D. MacBeth (1973): Risk, return, and equilibrium: Empirical tests, Journal of Political Economy, Vol. 81, No. 3, 607-636.

Fama, Eugene F. and Kenneth R. French (1993): Common risk factors in the returns on stocks and bonds, Journal of Financial Economics, Vol. 33, No. 1, 3-56.

Fama, Eugene F. and Kenneth R. French (1996): Multifactor explanations of asset pricing anomalies, Journal of Finance, Vol. 51, No. 1, 55-84.

Fischbacher, Urs (2007): z-Tree: Zurich toolbox for ready-made economic experiments, $E x$ perimental Economics, forthcoming.

Frazzini, Andrea (2006): The disposition effect and underreaction to news, Journal of Finance, Vol. 61, No. 4, 2017-2046.

Garvey, Ryan and Anthony Murphy (2004): Are professional traders too slow to realize their losses?, Financial Analysts Journal, Vol. 60, No. 4, 35-43.

Genesove, David and Christopher Mayer (2001): Loss aversion and seller behavior: Evidence from the housing market, Quarterly Journal of Economics, Vol. 116, No. 4, 12331260.

Gneezy, Uri, Arie Kapteyn, and Jan Potters (2003): Evaluation periods and asset prices in a market experiment, Journal of Finance, Vol. 58, No. 2, 821-837.

Goetzmann, William N. and Massimo Massa (2004): Disposition matters: Volume, volatility and price impact of a behavioral bias, working paper. 
Greenwald, Anthony G. (1980): The totalitarian ego: Fabrication and revision of personal history, American Psychologist, Vol. 35, No. 7, 603-618.

Grinblatt, Mark and Bing Han (2005): Prospect theory, mental accounting, and momentum, Journal of Financial Economics, Vol. 78, No. 2, 311-339.

Haigh, Michael S. and John A. List (2005): Do professional traders exhibit myopic loss aversion? An experimental analysis, Journal of Finance, Vol. 60, No. 1, 523-534.

Hong, Harrison and Jeremy C. Stein (1999): A unified theory of underreaction, momentum trading, and overreaction in asset markets, Journal of Finance, Vol. 54, No. 6, 21432184.

Jegadeesh, Narasimhan (1990): Evidence of predictable behavior of security returns, Journal of Finance, Vol. 45, No. 3, 881-898.

Jegadeesh, Narasimhan and Sheridan Titman (1993): Returns to buying winners and selling losers: Implications for stock market efficiency, Journal of Finance, Vol. 48, No. 1, 65-91.

Jegadeesh, Narasimhan and Sheridan Titman (2001): Profitability of momentum strategies: An evaluation of alternative explanations, Journal of Finance, Vol. 56, No. 2, 699720.

Johnson, Timothy C. (2002): Rational momentum effects, Journal of Finance, Vol. 57, No. 2, 585-608.

Kahneman, Daniel and Amos Tversky (1973): On the psychology of prediction, Psychological Review, Vol. 80, No. 4, 237-251.

Kahneman, Daniel and Amos Tversky (1979): Prospect theory: An analysis of decision under risk, Econometrica, Vol. 47, No. 2, 263-292.

Langer, Ellen J. (1975): The illusion of control, Journal of Personality and Social Psychology, Vol. 32, No. 2, 311-328. 
Lichtenstein, Sarah, Baruch Fischhoff, and Lawrence Phillips (1982): Calibration of probabilities: The state of the art to 1980, in: Daniel Kahneman, Paul Slovic, and Amos Tversky (eds.): Judgment under uncertainty: Heuristics and biases, New York, Cambridge University Press, 306-334.

Miller, Dale T. and Michael Ross (1975): Self-serving bias in the attribution of causality: Fact or fiction?, Psychological Bulletin, Vol. 82, No. 2, 213-225.

Moskowitz, Tobias J. and Mark Grinblatt (1999): Do industries explain momentum, Journal of Finance, Vol. 54, No. 4, 1249-1290.

Odean, Terrance (1998): Are investors reluctant to realize their losses?, Journal of Finance, Vol. 53, No. 5, 1775-1798.

Plott, Charles R. and Shyam Sunder (1982): Efficiency of experimental security markets with insider information: An application of rational-expectations models, Journal of Political Economy, Vol. 90, No. 4, 663-698.

Plott, Charles R. and Shyam Sunder (1988): Rational expectations and the aggregation of diverse information in laboratory security markets, Econometrica, Vol. 56, No. 5, 10851118.

Rouwenhorst, K. Geert (1998): International momentum strategies, Journal of Finance, Vol. 53, No. 1, 267-284.

Rouwenhorst, K. Geert (1999): Local return factors and turnover in emerging stock markets, Journal of Finance, Vol. 54, No. 4, 1439-1464.

Schiereck, Dirk, Werner De Bondt, and Martin Weber (1999): Contrarian and momentum strategies in Germany, Financial Analysts Journal, Vol. 55, No. 6, 104-116.

Shefrin, Hersh and Meir Statman (1985): The disposition to sell winners too early and ride losers too long: Theory and Evidence, Journal of Finance, Vol. 40, No. 3, 777-790.

Shleifer, Andrei and Robert W. Vishny (1997): The limits of arbitrage, Journal of Finance, Vol. 52, No. 1, 35-55.

Shumway, Tyler and Guojun Wu (2006): Does disposition drive momentum?, working paper. 
Svenson, Ola (1981): Are we less risky and more skillful than our fellow drivers?, Acta Psychologica, Vol. 47, No. 2, 143-148.

Thaler, Richard H. (1980): Toward a positive theory of consumer choice, Journal of Economic Behavior and Organization, Vol. 1, No. 1, 39-60.

Thaler, Richard H. (1985): Mental accounting and consumer choice, Markting Science, Vol. 4, No. 3, 199-214.

Tversky, Amos and Daniel Kahneman (1974): Judgment under uncertainty: Heuristics and biases, Science, Vol. 185, No. 4157, 1109-1186.

Tversky, Amos and Daniel Kahneman (1992): Advances in prospect theory: Cumulative representation of uncertainty, Journal of Risk and Uncertainty, Vol. 5, No. 4, 297-323.

Weber, Martin and Colin F. Camerer (1998): The disposition effect in securities trading: An experimental analysis, Journal of Economic Behavior and Organization, Vol. 33, No. 2, 167-184.

Weber, Martin and Frank Welfens (2007): An individual-level analysis of the disposition effect: Empirical and experimental evidence, working paper.

Wu, Xueping (2002): A conditional multifactor analysis of return momentum, Journal of Banking and Finance, Vol. 26, No. 8, 1675-1696. 


\section{Figure 1: Fundamental shocks and market reaction}

The figure shows three hypothetical reactions in equilibrium market prices succeeding a single positive fundamental shock from 100 to 200 currency units in $t=100$. We display market prices to underreact, to overreact, or to oscillate around the fundamental value.

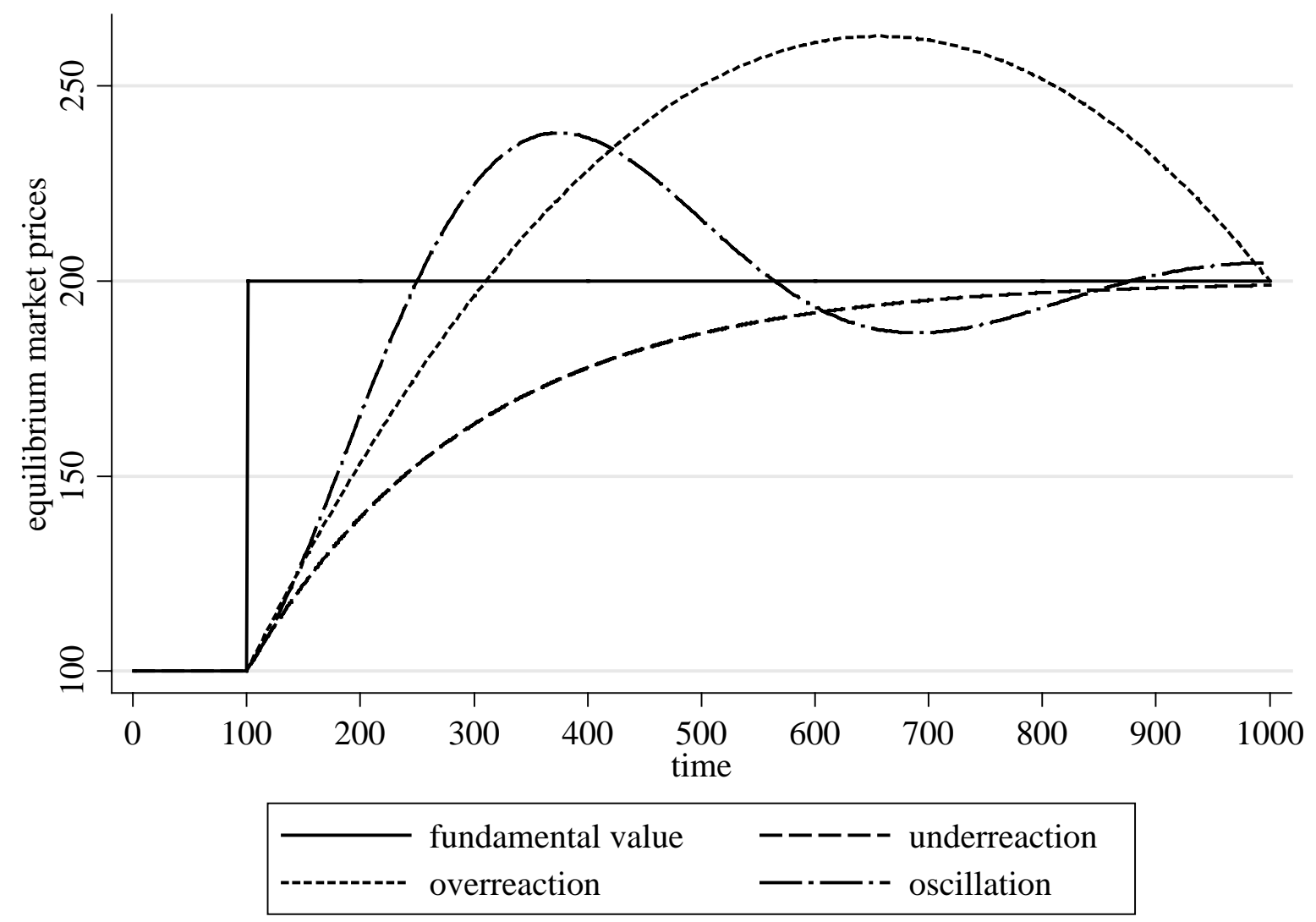




\section{Figure 2: Computer screen}

The figure shows a translation of the computer screen for the market experiment. In the upper left-hand part of the screen, subjects are informed about the remaining states and corresponding values of the good. Beneath this box, we display the subject's current endowment of goods and money on account. On the right-hand side, three gray boxes document selling offers, purchasing offers, and last transaction prices, with selling offers sorted lowest to highest, purchasing offers sorted highest to lowest, and last transaction prices in chronological order. Below these boxes, subjects could enter their own purchasing and selling offers. The subject's own offers are displayed in blue color in the gray information boxes. The screen was explained to subjects in a preceding tutorial session.

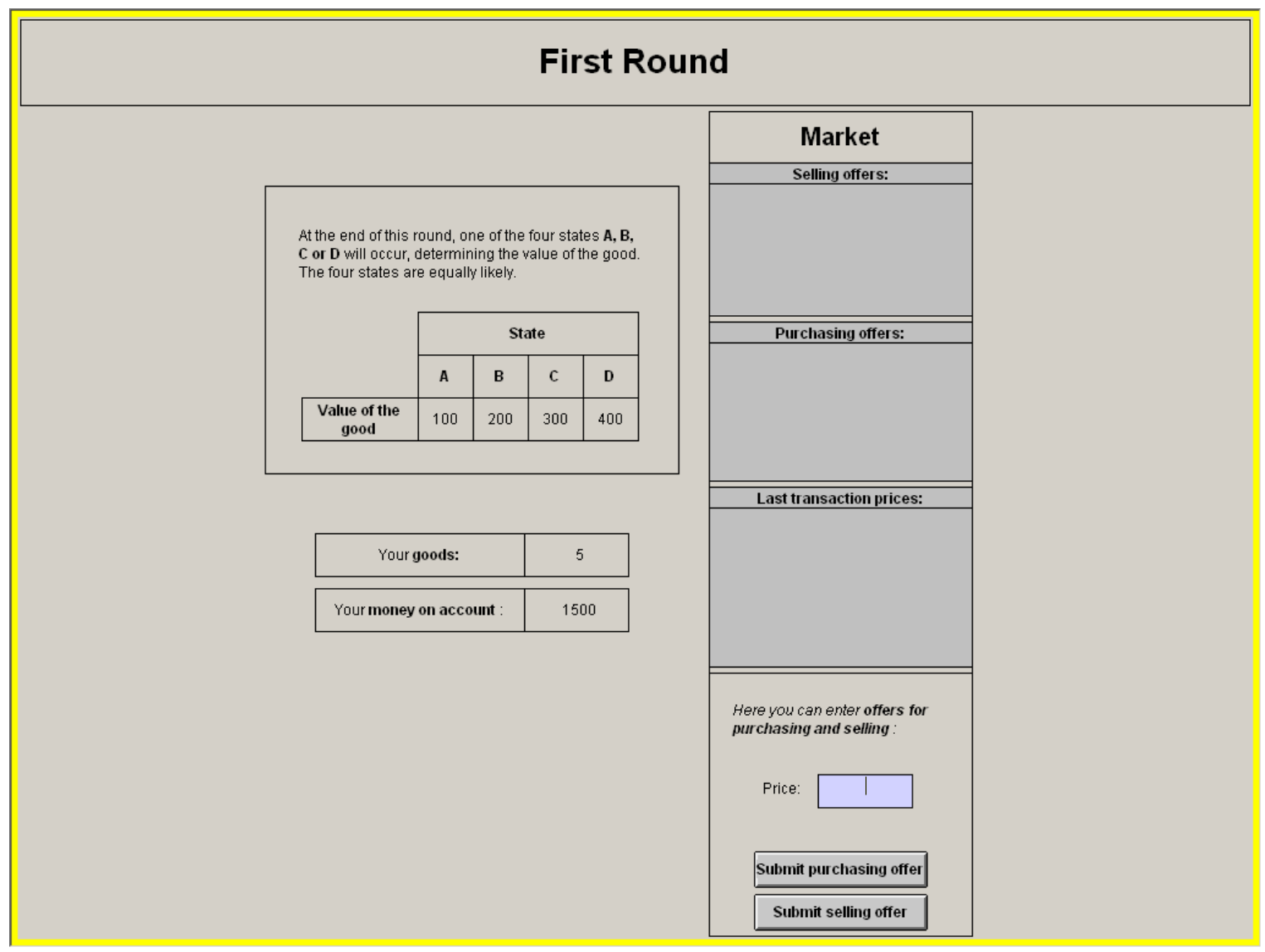


Figure 3: Course of the experiment

The figure visualizes the course of the market experiment for one round. Every experimental session consists of a total of ten rounds.

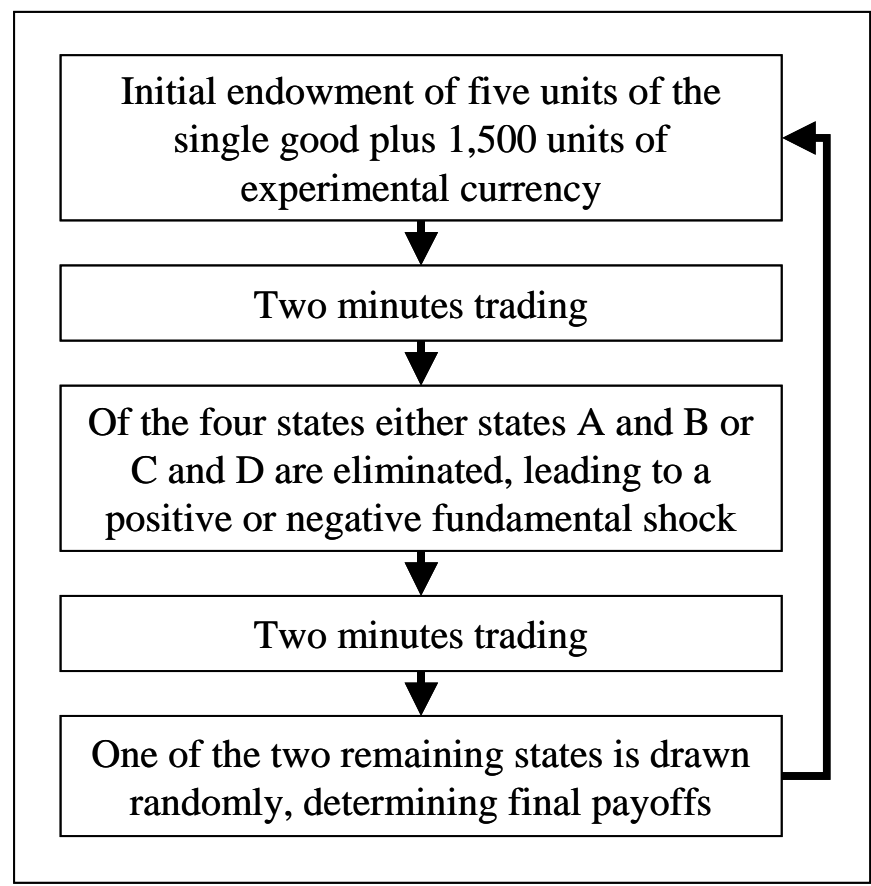




\section{Figure 4: Average transaction prices preceding and succeeding the shock}

The first graph shows average transaction prices preceding the fundamental shock, i.e. over the first 120 seconds of trading. The second and third graphs show the same information succeeding the shock, i.e. for the later 120 seconds. Average transaction prices plotted in the graphs are calculated for every second. The dashed line is based on an asymptotic fit to these averages. Expected values are drawn with a solid line.
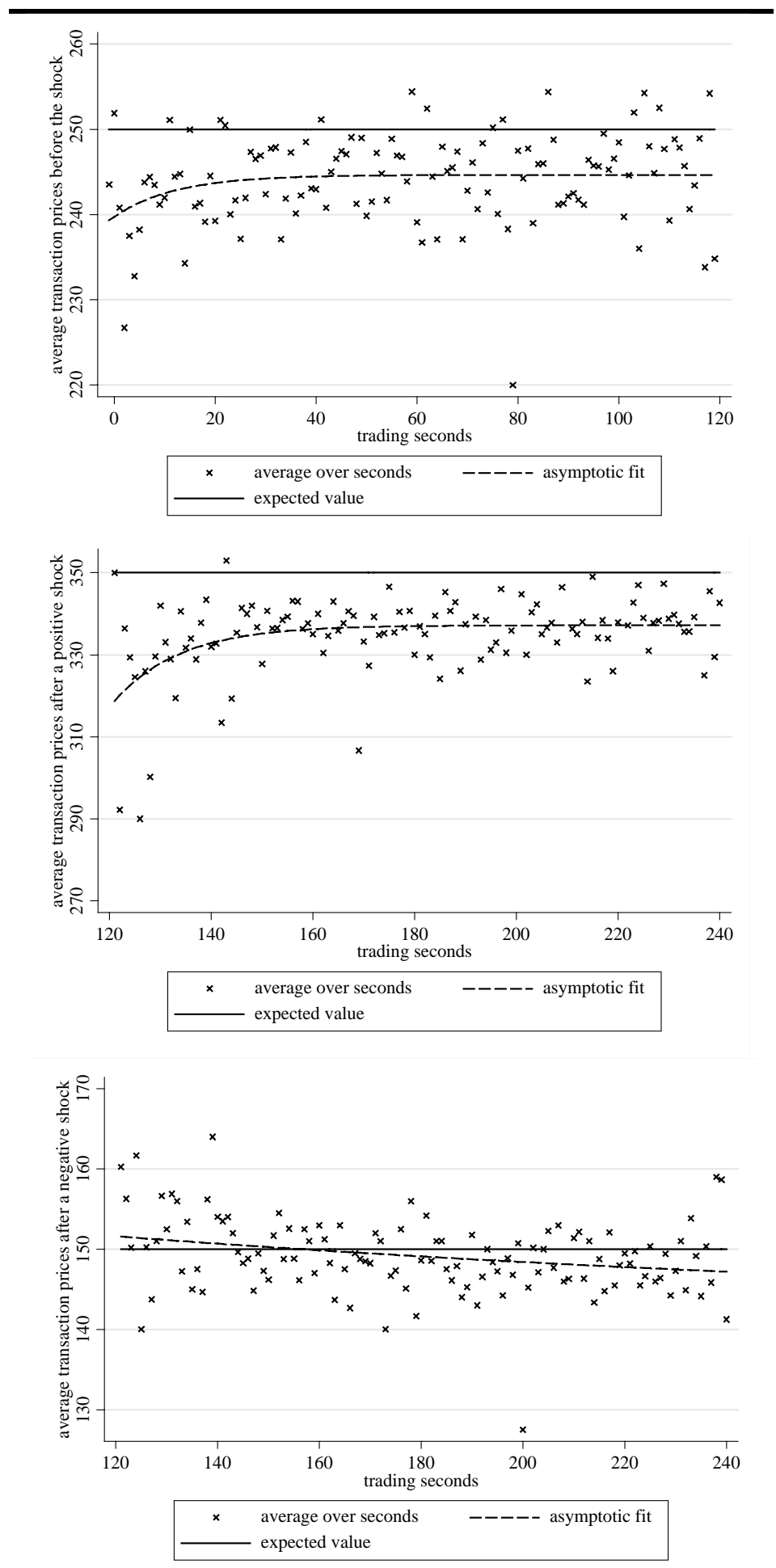
Figure 5: Average transaction prices and market disposition (sorting: ind. choice)

The following graphs show average transaction prices succeeding a positive or negative fundamental shock, i.e. over the later 120 seconds of trading, for high-disposition and low-disposition markets separately. Subjects were assigned to one of the two markets based on their individual disposition effects in a preceding individual choice task. The expected value of one unit of the single good, here drawn with a solid line, equals 350 or 150 experimental currency units. Average transaction prices plotted in the graphs are calculated for every second. The dashed lines are based on asymptotic fits to these averages. Median transaction prices lead to similar pictures.
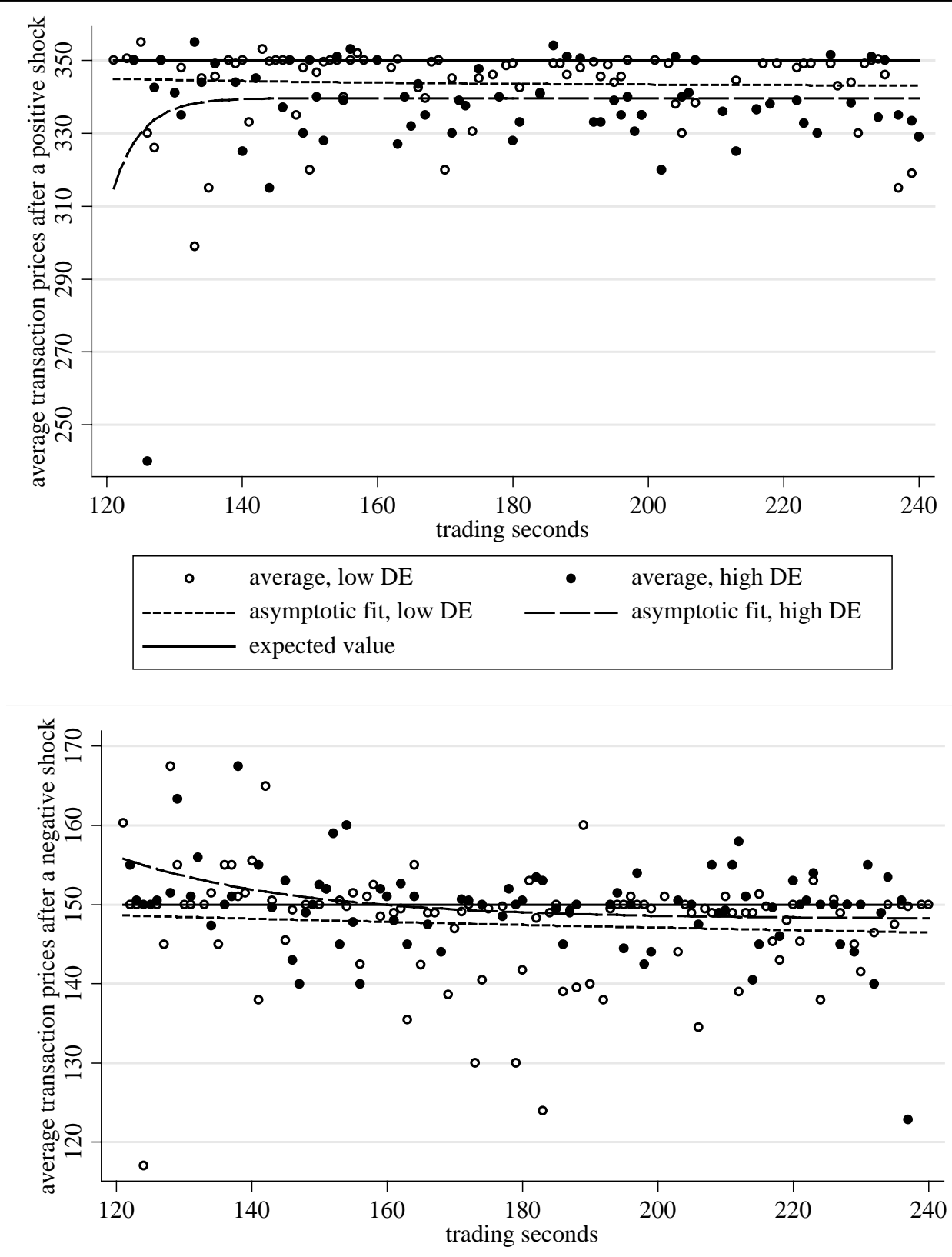

- average, low DE $\quad$ average, high DE

asymptotic fit, low DE ——— asymptotic fit, high DE

expected value 


\section{Figure 6: Average transaction prices and market disposition (sorting: rounds 1 - 4)}

The following graphs show average transaction prices succeeding a positive or negative fundamental shock, i.e. over the later 120 seconds of trading, for high-disposition and low-disposition markets separately. Subjects were assigned to one of the two markets based on their individual disposition effects in the first four rounds of trading. The expected value of one unit of the single good, here drawn with a solid line, equals 350 or 150 experimental currency units. Average transaction prices plotted in the graphs are calculated for every second. The dashed lines are based on asymptotic fits to these averages. Median transaction prices lead to similar pictures.
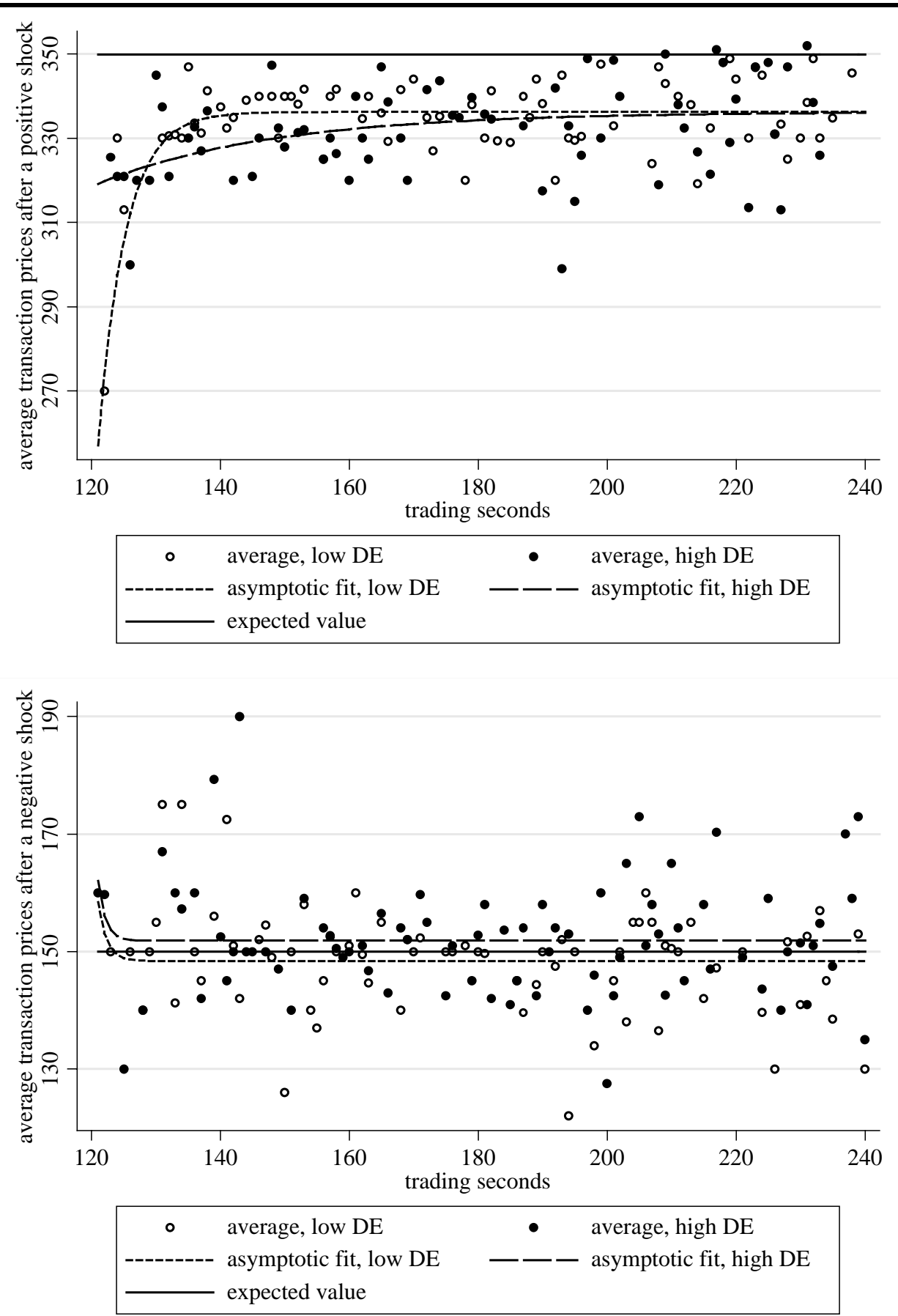


\section{Table 1: Trading volume and order placement}

This table reports the average number of transactions as well as the average number of purchasing and selling orders before the fundamental shock, following positive fundamental shocks, and following negative fundamental shocks, respectively. Averages are calculated over rounds and over time intervals of twenty seconds each. Medians do not differ strongly from the reported means.

Average \# of Average \# of transactions purchasing orders

\section{Table 2: Underreaction in transaction prices following gains and following losses}

This table shows mean and median underreaction in transaction prices as well as the proportion of underreacting transactions succeeding the fundamental shock. Following a positive shock, market underreaction is calculated as the difference between fundamental values and transaction prices. Conversely, succeeding a negative shock, underreaction measures are defined as transaction prices minus fundamental value. Fundamental values are approximated as expected values minus an average risk premium of 1 experimental currency unit. Underreaction measures are calculated for every single transaction and thereafter averaged over time intervals of twenty seconds each. Measures are provided separately for price paths succeeding positive and negative fundamental shocks. The first and second p-values are based on binomial tests, which analyze whether most transactions succeeding positive or negative shocks are at underreacting prices. The last p-value is based on a ranksum test comparing the degree of underreaction following positive and negative changes in fundamental value.

Positive shocks Negative shocks

\begin{tabular}{|c|c|c|c|c|c|c|c|c|c|}
\hline Seconds & Mean & Median & Prop. & Mean & Median & Prop. & $\begin{array}{c}\mathrm{p} \\
\text { (pos.) }\end{array}$ & $\begin{array}{c}\mathrm{p} \\
\text { (neg.) }\end{array}$ & $\begin{array}{c}\mathrm{p} \\
\text { (diff.) }\end{array}$ \\
\hline $1-20$ & 19.80 & 16 & 79.19 & 2.89 & 1 & 77.19 & 0.0000 & 0.0000 & 0.0000 \\
\hline $21-40$ & 15.46 & 10 & 73.98 & 0.91 & 1 & 64.63 & 0.0000 & 0.0000 & 0.0000 \\
\hline $41-60$ & 13.47 & 11 & 82.11 & -0.86 & 1 & 56.83 & 0.0000 & 0.0633 & 0.0000 \\
\hline $61-80$ & 14.22 & 11 & 91.22 & -1.69 & 0 & 48.41 & 0.0000 & 0.6839 & 0.0000 \\
\hline $81-100$ & 13.41 & 11.5 & 87.90 & -0.36 & 1 & 58.90 & 0.0000 & 0.0191 & 0.0000 \\
\hline $101-120$ & 11.41 & 11 & 82.30 & -2.27 & 1 & 55.86 & 0.0000 & 0.0919 & 0.0000 \\
\hline
\end{tabular}




\section{Table 3: Momentum price drifts following gains and following losses}

This table shows mean and median momentum price drifts succeeding the fundamental shock as well as the proportion of rounds exhibiting positive or negative momentum. For determining momentum price drifts, we first calculate average transaction prices for every round and every time interval of twenty seconds each. We then measure momentum drifts for rounds exhibiting underreacting prices as the change in average transaction prices from interval to interval. The first row displays, e.g., average price changes between the first and the second interval, i.e. over seconds 1 to 40. All measures are displayed separately for positive and negative fundamental shocks. The first and second p-values are based on binomial tests, which analyze whether most rounds succeeding positive (negative) shocks exhibit positive (negative) momentum drifts. The last p-value is based on a ranksum test comparing absolute momentum price drifts following positive and negative changes in fundamental value. We perform the test for all rounds exhibiting price drifts into the direction of the fundamental shock.

Positive shocks Negative shocks

\begin{tabular}{cccccccccc} 
Seconds & Mean & Median & Prop. & Mean & Median & Prop. & (pos.) & (neg.) & (diff.) \\
\hline $1-40$ & +6.93 & +4.17 & 75.68 & -2.83 & 0.00 & 58.06 & 0.0013 & 0.2366 & 0.6347 \\
$21-60$ & +1.14 & +0.25 & 53.33 & -4.75 & -1.50 & 75.68 & 0.4278 & 0.0013 & 0.9483 \\
$41-80$ & +0.25 & 0.00 & 48.65 & -1.49 & -0.50 & 64.29 & 0.6286 & 0.0925 & 0.4775 \\
$61-100$ & +1.96 & +0.13 & 52.63 & -0.70 & -0.25 & 72.00 & 0.4357 & 0.0216 & 0.0120 \\
$81-120$ & +0.28 & 0.00 & 50.00 & -0.02 & 0.00 & 55.56 & 0.5747 & 0.3506 & 0.1518 \\
\hline
\end{tabular}

\section{Table 4: Underreaction in high-disposition and low-disposition markets}

This table shows mean and median underreaction in transaction prices succeeding the fundamental shock. Following a positive shock, market underreaction is calculated as the difference between fundamental values and transaction prices. Succeeding a negative shock, underreaction measures are defined as transaction prices minus fundamental value. Fundamental values are approximated as expected values minus an average risk premium of 1 experimental currency unit. Underreaction measures are displayed for trades succeeding positive and negative fundamental shocks as well as for high-disposition and low-disposition markets. Participants are assigned to one of the two markets either based on their decisions in an individual choice task or on their trading behavior in the first four rounds of the market experiment. The p-value is based on a ranksum test comparing average underreaction in high-disposition and low-disposition markets.

$$
\text { High-disposition Low-disposition }
$$

\begin{tabular}{llccccc} 
Shock & Sorting & Mean & Median & Mean & Median & $\mathrm{p}$ \\
\hline \multirow{2}{*}{ Positive } & Individual choice & 10.83 & 9 & 5.90 & 0 & 0.0017 \\
& First four rounds & 17.18 & 17 & 14.22 & 14 & 0.0464 \\
\hline \multirow{2}{*}{ Negative } & Individual choice & -0.12 & 1 & -1.30 & 1 & 0.0031 \\
& First four rounds & 3.40 & 1 & -1.13 & 1 & 0.0340 \\
\hline
\end{tabular}




\section{Table 5: Momentum price drifts in high-disposition and low-disposition markets}

This table shows mean and medium momentum price drifts succeeding the fundamental shock. For determining momentum price drifts, we first calculate average transaction prices for every round and both the first 20 and the last 20 seconds of the 120 -seconds trading period. We then measure momentum drifts for all rounds exhibiting underreacting average transaction prices in the first 20 seconds as the change in average transaction prices from the first 20 seconds to the last 20 seconds. Momentum measures are displayed for positive and negative fundamental shocks as well as for high-disposition and low-disposition markets. Participants are assigned to one of the two markets either based on their decisions in an individual choice task or on their trading behavior in the first four rounds of the market experiment. The p-value is based on a ranksum test comparing momentum price drifts in high-disposition and low-disposition markets.

$$
\text { High-disposition Low-disposition }
$$

\begin{tabular}{llccccc} 
Shock & Sorting & Mean & Median & Mean & Median & $\mathrm{p}$ \\
\hline \multirow{2}{*}{ Positive } & Individual choice & +15.24 & +4.17 & +14.81 & +19.50 & 0.5211 \\
& First four rounds & +4.31 & +3.50 & +2.73 & +5.93 & 0.9654 \\
\hline \multirow{2}{*}{ Negative } & Individual choice & -9.52 & -5.00 & -8.03 & -10.00 & 0.5209 \\
& First four rounds & -19.38 & -17.50 & -5.33 & -0.58 & 0.2531 \\
\hline
\end{tabular}

